\title{
GEOINFORMATICS EDUCATION IN CHINA
}

\author{
Deren Li, Jianya Gong, Peng Yue \\ State Key Laboratory of Information Engineering in Surveying, Mapping and Remote Sensing (LIESMARS), \\ Wuhan University, 129 Luoyu Road, Wuhan, 430079, China \\ Email:drli@whu.edu.cn
}

\section{Commission VI}

KEY WORDS: Geoinformatics, Surveying and Mapping, Remote Sensing Science and Technology, Geographical Information Science (GIS), Education and Training, China

\begin{abstract}
:
The paper will give an overview of the current status of education in Geoinformatics in China. First, the paper will provide a general review of the scientific and technological development of Geoinformatics in China. It then presents how the development affects the education and training in China. In the paper, universities and institutes in China that can award academic degrees related to Geoinformatics will be summarized. Next, the paper will report the work having been done by the expert group on Surveying and Mapping, including the revision of discipline catalogue and guide for graduate education and requirements. A list of typical curriculain Geoinformatics education is suggested. Finally, activities on promoting the graduate student exchange platform will be presented.
\end{abstract}

\section{OVERVIEW}

Geoinformatics education has progressed significantly in recent decades in China. For example, more than two hundred universities have academic programs on Geographical Information Science (GIS), and about 10,000 students graduate each year with degrees in GIS.China's education system groups disciplines into a three-level catalogue. At the first level, Geoinformatics covers both Science and Engineering disciplines in China (Figure 1). In the category of Science, Geography, in particular its sub-discipline GIS, is the major body contributing to Geoinformatics education. In the category of Engineering, Surveying and Mapping discipline, contributes to education in Geoinformatics. The Surveying and Mapping is further classified into two sub-disciplines at the third level of the discipline catalogue: Geomatics Engineering, and Remote Sensing Science and Technology. These disciplines reflect the undergraduate education in Geoinformatics in China.



Figure 1. Undergraduate education in Geoinformatics

Aforementioned disciplines focuses on the education at the undergraduate level. At the graduate education level, China's education system has more flexibility and fine-grained sub-disciplines. In the past several years, the Ministry of Education (MOE) of China and Academic Degrees Board of the National Council of China (ADBNCC) set up expert groups to evaluate each discipline. They maintain a discipline catalogue for graduate education programs and update it when necessary. In the catalogue, the Surveying and Mapping includes three sub-disciplines, Geodesy \& Surveying Engineering, Photogrammetric Engineering \& Remote Sensing, and Cartography \& Geographical Information Engineering. In the past decade, experts and educationalists in Surveying and Mapping found that the three sub-disciplines are not enough to meet the graduate education and training in the domain. We need more graduate programs targeted to the updated and extended domains. Since 2009, experts in the group of the Surveying and Mapping disciplineof ADBNCC, started to work on updating the catalogue for their discipline. These experts come from Wuhan University, National Geomatics Center of China, Southwest Jiaotong University, Tongji University, the PLA Information Engineering University, and China University of Geosciences. They work with experts from other graduate educational units in China to develop fine-grained sub-disciplines and propose a common guide for graduate program and education. As a result, three more sub-disciplines are added into the Surveying and Mapping. They are Navigation and Location-based Service, Mine and Underground Surveying, and Hydrographic Surveying and Charting (Figure 2). A new version of document on "Brief Introduction to Surveying and Mapping" was just released in 2013 to include the latest scientific and technological development of the discipline and updated sub-disciplines.

In terms of graduate education and training, basic requirements for achieving doctoral or master's degrees were issued as a guide for each graduate education unit/organization in China. The requirements include literacy, professional skills, knowledge structure, academic capabilities, thesis writing, and dissertation defence. All these requirements will provide a reference guide for evaluate the qualities of graduate education and training in different universities in China. In addition, under 
the sponsorship of MOE and ADBNCC, a student exchange platform has been established in the Surveying and Mapping discipline. The platform includes a series of doctoral forums and summer schools held by different universities. One typical example is the summer schools held annually by State Key Laboratory of Information Engineering in Surveying, Mapping and Remote Sensing (LIESMARS) of Wuhan University. These academic activities attract hundreds of students from China and even other countries. The platform prompts the sharing of high-quality education resources, information and knowledge exchanges, and regional and international collaborations, and improves capabilities of students.

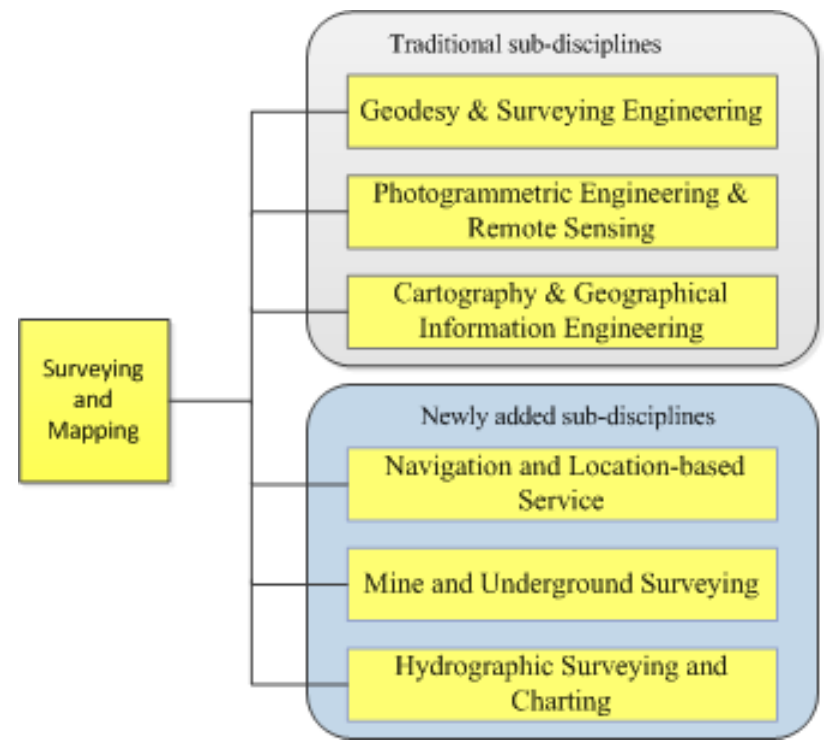

Figure 2. Updated sub-disciplines of Surveying and Mapping

The remainder of the paper will introduce some latest work on Geoinformatics education, including the revision of discipline catalogue and guide for graduate education and requirements. A list of typical curriculain Geoinformatics education is also given Finally, activities on promoting the student exchange platform are presented.

\section{REVISION OF DISCIPLINE CATALOGUE}

With the increasing demand of geospatial information in various application domains, Geoinformatics industry market in Chinagains rapid development in the past decade. Statistics show that the China'sGeoinformaticsmarket is worth around 200 billion RMB. The goal is to reach up to 1,000 billion RMB by the year 2020, expected by the National Administration for Surveying and Mapping and Geoinformation (NASMG). It is estimated that there are over 400,000 employees and 20,000 licensed organization and enterprises involved in Geoinformatics industry in China (NASMG, 2012). China's industry structure on Geoinformaticshas also gone through significant changes in recent years, including more specified domain markets. Traditional education and training systems do not satisfy the increasingly changing demands of employment market. For example, the Surveying and Mapping has expanded from traditional disciplines to navigation, Earth observation, mineral science, and marine science.

In order to meet demands of Geoinformaticsindustry and provide well-educated people for the changingemployment market, the expert group on Surveying and Mapping disciplinefrom ADBNCCupdates the discipline catalogue by adding three more sub-disciplines, namely Navigation and Location-based Service, Mine and Underground Surveying, andHydrographic Surveying and Charting. The technologies and methodologies for the Surveying and Mapping disciplinehave been extended to the planning and management of underground and ocean resources, as well as sovereignty, territory, and public security.For example, thesub-discipline,Navigation and Location-based Service, which involves satellite positioning, internet of things, disaster management, and smart weapons, plays a significant role insocial economy andnational security. The Mine and Underground Surveying sub-discipline provides accurate, timely, and reliable spatial information and decision support for exploitation of mineral resources, utilization of underground space, disaster rescue, and environmental protection of the ground surface. The Hydrographic Surveying and Charting becomes more and more important in China, since China is a country with a vast maritime territory, having a mainland coastline of about 18 thousand kilometers and more than 6500 islands. Hydrographic Surveying and Charting is an essential discipline formaritime navigation, marine construction, development of rich sea resources, and protection of marine rights and interests.

A new version of document on "Brief Introduction to Surveying and Mapping" was released recently in 2013. It includes development history, contents, scope, cultivation target, and related disciplines of Surveying and Mapping discipline. Surveying and Mapping is a science and technology to study the acquisition, storage, processing, analysis, management, transmission, presentation, distribution, and application of spatially and temporally related information about the Earth or other planets. It has a close relation with Geophysics, Geology, Astronomy, Geography, Marine Science, Space Science, Environmental Science, Computer Science and Information Science, and many other engineering disciplines.

Statistics show that the number of personnel with master or higher degrees increased 2.2 times from 2005 to 2012. More than 200 universities and over 20 vocational schools have Geoinformatics related programs, and more than 200 research institutions conduct Geoinformaticsresearch. Every year about 10 thousand students graduate with degrees in GIS. Hence the education quality of students in Geoinformaticsis very important in China. Under the guidance of the ADBNCC, the expert group on Surveying and Mapping disciplinealsoevaluatesuniversities and institutes that are qualified to award doctoral degreesin Surveying and Mapping.The following 9 universities in China are certified to award doctor degrees of Surveying and Mapping.

- Wuhan University (Wuhan)

- Tongji University (Shanghai)

- Shandong University of Science and Technology (Qingdao)

- Central South University (Changsha)

- Liaoning Technical University (Fuxin)

- Peking University (Beijing)

- Southwest Jiaotong University (Chengdu)

- PLA Information Engineering University (Zhengzhou)

- China University of Mining Technology (Xuzhou)

\section{GUIDE FOR GRADUATE EDUCATION AND REQUIREMENTS}

In order to satisfy industrial demands for high-quality professional and technical personnel in Geoinfomatics, the 
expert group on Surveying and Mapping of ADBNCC works with representatives from Geoinformatics related organizations and enterprises, and proposes a common guide for graduate

Table 1. Curricula for Ph.D. program

\begin{tabular}{|c|c|c|}
\hline Course Item & Courses & Credit Hours \\
\hline \multirow{4}{*}{ Basic courses of comprehensive education } & Modern Science Technology Revolution and Marxism & 2 \\
\hline & English & 2 \\
\hline & Special Lectures taught in English & 2 \\
\hline & Second Foreign Language & 2 \\
\hline \multirow{7}{*}{$\begin{array}{c}\text { Specialized courses } \\
\text { (Choose at least three courses) }\end{array}$} & Modern Photogrammetry & 2 \\
\hline & $\begin{array}{l}\text { Processing and application of High-resolution remote sensed } \\
\text { information }\end{array}$ & 2 \\
\hline & $\begin{array}{l}\text { Geographic information computation and Web Service } \\
\text { technology }\end{array}$ & 2 \\
\hline & Multi-mode navigation and positioning and LBS & 2 \\
\hline & Intelligent cartography & 2 \\
\hline & Modern geodesy and Geodetic Data Processing & 2 \\
\hline & Lecture Notes of Modern Science \& Technology & 1 \\
\hline
\end{tabular}

program and education. The common guide includes the basic requirements for graduate students and provides a list of curricula for doctor and master education.

\subsection{Basic requirements for graduate students}

The basic requirements for graduate students include literacy, professional skills, knowledge structure, academic capabilities, thesis writing, and dissertation defence.The literacy section requires that the graduate students have capabilities to read professional literature smoothly and write academic articles. The professional skills indicate that the graduate students are capable of doing Geoinformatics related technical works. The knowledge structure specifies the knowledge that a graduate student should master, including basic materials and specified contents. The academic capabilities include the capability of acquiring knowledge, conducting scientific research, critical thinking and innovation. As concerned to thesis writing, it is the comprehensive reflection of one's research findings. It should be normativein format and complete in content with systematic method and sufficient experiments. For the $\mathrm{Ph}$. D students, their thesis should be peer-reviewed by at least 3 professors in Geoinformatics disciplines before going to the dissertation defence.

Geoinformatics education in China includes undergraduate and graduate educational levels. The graduate level includes doctor and master degrees programs. The doctor degree program usually takes about 3 to 6 years for students to complete. A $\mathrm{Ph} . \mathrm{D}$. student is required to publish at least one peer-reviewed academic paper as a reflection of academic capabilities. The master degree program is further classified into academic master degree (full-time, 3 years) and professional master degree (full-time, 2 years). The academic master degree is offered for those students who want to conduct scientific researches, while the professional master degree is oriented to cultivate professional and skilful personnel for employment market. The candidate for academicmaster degree program is generally required to publish a peer-reviewed conference paper or an article in referred journal related to Geoinformatics. Compared with the 3 yearsprogram, the professional master degree program has less time and lower creditsrequired for the program. However, it assigns more credit hours for professional practices. This programhelps students connect their theoretical knowledge with practices in Geoinformatics by exposing them to the real working environment. It meets growing demands for Geoinformatics personnel and benefitsgraduates'early employment. Moreover, another kind of master degree program, named engineering master degree program (part-time, 2-3 years) is also offered by some universities totrainqualified engineers for industrial enterprises.

\subsection{Recommended curricula for M.S. \& Ph.D. students}

To better delivering latest research and knowledge in Geoinformatics, experts from ADBNCCsuggest a list of curricula for doctor and master degree programs, listed in Table 1 and 2 respectively. The $\mathrm{Ph}$. D. students will spend more time on academic researches, and thus take less course studies. The curricula suggest 11 courses totally for the Ph.D. program. Each credit means 18 lecture hours. Table 1 shows that the courses are grouped into two categories: basic courses, and specialized courses. The basic courses are necessary for all Ph.D. students. The specialized courses are optional for Ph.D. students, yet students are required to choose at least three courses from this category.

\section{Credit hours for master degree courses}

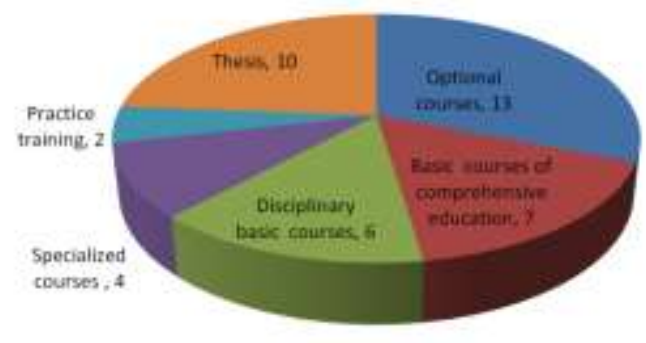

Figure 3. Credit hours distribution for the master degree program 
The credit requirement for the master degree program is shown in Figure 3. It assigns 10 credits for thesis writing and 2 credits for practice training. At least 30 credits of course learning, including at least 7 credits for basic courses of comprehensive education, 6 for disciplinary basic courses and 4 for specialized courses.

Table 2. Curricula for M.S. program

\begin{tabular}{|c|c|c|c|}
\hline Course Item & Courses & $\begin{array}{l}\text { Credit } \\
\text { Hours }\end{array}$ & Remarks \\
\hline \multirow{6}{*}{$\begin{array}{l}\text { Basic courses of } \\
\text { comprehensive } \\
\text { education }\end{array}$} & $\begin{array}{l}\text { Theory and Practice of Socialism with Chinese } \\
\text { Characteristics }\end{array}$ & 2 & \\
\hline & Dialectics of Nature & 1 & \\
\hline & English & 2 & \\
\hline & Matrix Theory & 2 & \multirow{3}{*}{ At least one is required } \\
\hline & Numerical Analysis & 2 & \\
\hline & Advanced Algebra & 2 & \\
\hline \multirow{6}{*}{$\begin{array}{c}\text { Disciplinary } \\
\text { basic courses }\end{array}$} & Theory and Methods of Measurement Data Processing & 2 & \multirow{6}{*}{ Choose any three courses } \\
\hline & Space Geodesy & 2 & \\
\hline & Aerial and Space Photogrammetry & 2 & \\
\hline & $\begin{array}{l}\text { New Remote Sensing Information } \\
\text { Application Technique }\end{array}$ & 2 & \\
\hline & $\begin{array}{l}\text { Geographic Information Automatic Synthesis Principle and } \\
\text { Theory }\end{array}$ & 2 & \\
\hline & Geographic Information Theory and Technique & 2 & \\
\hline \multirow{8}{*}{$\begin{array}{l}\text { Specialized } \\
\text { courses }\end{array}$} & $\begin{array}{l}\text { Specialized English (Principle \& Application of Remote } \\
\text { Sensing) }\end{array}$ & 2 & \multirow{3}{*}{ At least one is required } \\
\hline & Specialized English (Spatial Statistics \& Analysis) & 2 & \\
\hline & $\begin{array}{l}\text { Specialized English (Digital Mapping \& Map } \\
\text { Generalization) }\end{array}$ & 2 & \\
\hline & Principle \& Application of GPS & 2 & \multirow{4}{*}{ At least one is required } \\
\hline & Digital Image Processing & 2 & \\
\hline & GIS Software Engineering & 2 & \\
\hline & 3S Integration \& Multi-Media Communication & 2 & \\
\hline & Lecture Notes of Modern Science \&Technology & 1 & At least 10 lectures \\
\hline \multirow{13}{*}{ Optional courses } & Second Foreign Language (German, French, Japanese) & 3 & \\
\hline & Hyperspectral Remote Sensing & 2 & \\
\hline & Microwave Remote Sensing & 2 & \\
\hline & Advanced Topics on Remote Sensing & 2 & \\
\hline & Research Methodology \& Scientific Writing & 1 & \\
\hline & Digital Terrain Surface Simulation \& its Methods & 2 & \\
\hline & InSAR & 2 & \\
\hline & Computer Network & 2 & \\
\hline & Web Geographic Information Systems and Services & 2 & \\
\hline & GPS/INS Combined Navigation and Application & 2 & \\
\hline & Principle of LIDAR \& Its Applications & 2 & \\
\hline & Technology \& Application of Satellite Gravity Surveying & 2 & \\
\hline & Development and Application of Thematic GIS & 2 & \\
\hline \multirow{5}{*}{$\begin{array}{l}\text { Supplementary } \\
\text { courses for } \\
\text { trans-disciplinary } \\
\text { students (Any } \\
\text { two courses) }\end{array}$} & The Principle of Photogrammetry & 0 & \multirow{5}{*}{$\begin{array}{c}\text { At least two courses for those } \\
\text { students who didn't major in } \\
\text { Geoinformatics at undergraduate } \\
\text { period }\end{array}$} \\
\hline & Principle and Methods of Remote Sensing & 0 & \\
\hline & The Principle of Geographic Information System & 0 & \\
\hline & Spatial Data Error Processing & 0 & \\
\hline & Digital Image Processing & 0 & \\
\hline
\end{tabular}

Other credits can be achieved by taking optional courses. The courses are grouped into five parts, and the corresponding required credits are shown in Figure 3. Table 2 lists 33 courses for the M.S. program. The basic courses of comprehensive education enables students have systematic training in social science, natural science, English learning and mathematics science. The disciplinary basic courses provide students with fundamental contents of Surveying and Mapping. The 
specialized courses focus on specialized, in-depth knowledge related to concrete research fields. Optional courses can be chosen according to one's research interests to achieve the total credits. Some supplementary courses are also provided for those students who are not major in Geoinformatics during the undergraduate period.

\section{GRADUATE STUDENT EXCHANGE PLATFORM}

To promote the sharing of high-quality education resources and support regional capacity development activities, the graduate student exchange platform has been established under the sponsorship of MOE and ADBNCC. The platform includes a series of doctoral forums and summer schools held by different universities. These academic exchange activities attract hundreds of students from China and even other countries.

\subsection{Doctoral forums}

The primary objective of doctoral forums is to provide doctoral students with opportunities for presenting their research projects and network with each other. The participants can benefit from the forums by receiving feedbacks on their thesis research from peers and invited senior researchers in the field. The doctoral forums are organized by different universities/institutes with different topics each year. The forum usually lasts for 3 to 4 days with no more than $100 \mathrm{Ph} . \mathrm{D}$. students being allowed to register. Free accommodations and meals are offered for registered $\mathrm{Ph}$. D students.Table 3 and Figure 4 show the related information about last three forums. The 2014 doctoral forum on "Surveying and Mapping and its application to the Western Development" will be held in Southwest Jiaotong University on May 10-11.

Table 3. Doctoral forums on Surveying and Mapping

2010 Held in China University of Mining and Technology (Xuzhou); 200 participants from 14 universities and institutes.

2011 Held in Information Engineering University (Zhengzhou); 38 invited senior researchers and $123 \mathrm{Ph}$. D students from 54 universities and institutes.

2012 Held in Tongji University (Shanghai); 10 invited senior researchers and $100 \mathrm{Ph}$. D students.

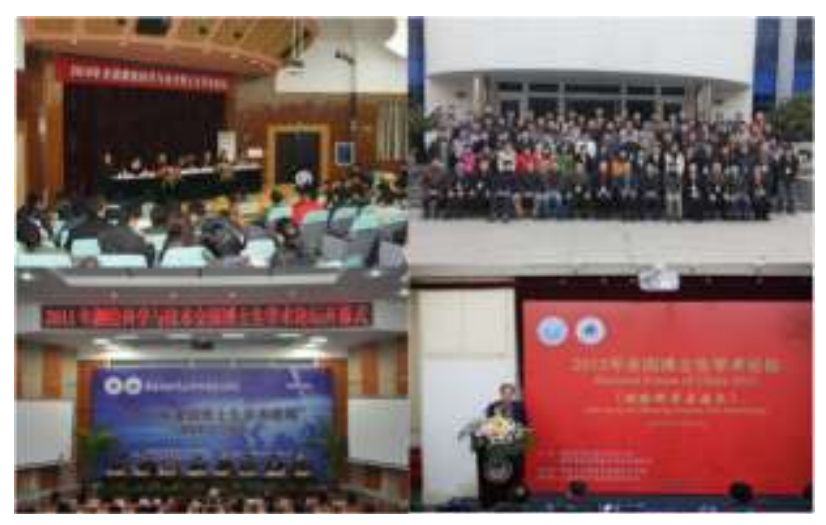

Figure 4. Doctoral forums

\subsection{Summer schools}

The Geoinformatics summer school, which usually lasts for 10 to 20 days, is a program organized by LIESMARS every year for attracting young students towards advanced studies and research in Geoinformatics (e.g. Figure 5). It is a good way of sharing high-quality education resources. Lots of top lecturers in Geoinformatics are invited to give lessens to summer school students. The summer school includes lecturers, courses, lab exercises, social events, and field trip. Apart from acquiring new knowledge, culture and nature experiences, it is an excellent opportunity for students and young researchers to meet highly esteemed scholars, young people from around the world and strengthen their networks.

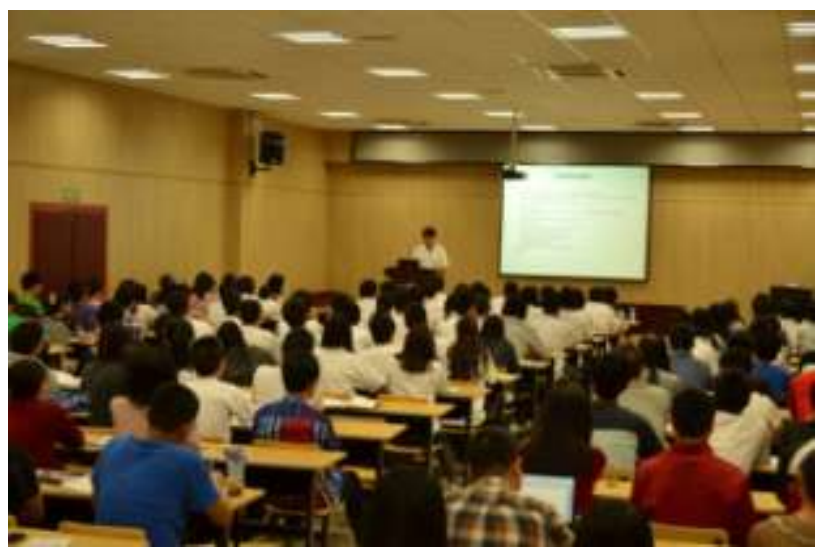

Figure 5. Summer school class

The 2014 Geoinformatics Summer Camp will be held from May $19^{\text {th }}$ to $28^{\text {th }}$, in conjunction with the Mid-Term Symposium of ISPRS Commission VI on Data, Information, and Knowledge Sharing for Geo-Education.Four teaching courses will be delivered, namely Geospatial Service Platform for Education and Research, Spatial Statistics, Mobile Laser Scanning and Mapping, and Open Source Mapmaking Technologies. In addition, course practice and student projects will be provided to help students strengthen the course contents. Detailed information is available at:

http://www.lmars.whu.edu.cn/isprscom6/summercamp.html. By now, about 200 students from all over the word have registered for this summer school.

\section{CONCLUDING REMARKS}

The paper gives an overview of the current status of Geoinformatics education in China, and review the work having been done by expert group on Surveying and Mapping. The expert group has made significant progress in Geoinformatics education in the last few years. Geoinformatics in China has become the pervasive technology for country's economic progress and industrialisation. Consequently, the education and training system in Geoinformatics can play an active role in the development of Geoinformatics industry. Furthermore, there is still a long way to go to improve the Geoinformatics education to a higher level.

\section{ACKNOWLEDGEMENS}

The work is supported by National Basic Research Program of China (2011CB707105), National Natural Science Foundation of China (41271397), and Program for New Century Excellent Talents in University (NCET-13-0435). 
The International Archives of the Photogrammetry, Remote Sensing and Spatial Information Sciences, Volume XL-6, 2014 ISPRS Technical Commission VI Symposium, 19 - 21 May 2014, Wuhan, China

\section{REFERENCES}

NASMG, 2012. The Status of Geospatial Information Management in China. http://ggim.un.org/2nd\%20Session/country\%20reports/Country \%20Report\%20China.pdf (Accessed 10Mar. 2013). 